\title{
Armazenamento não controlado na qualidade de sementes de Jatropha curcas $\mathbf{L}$.
}

\section{Non-controlled storage on Jatropha curcas L. seed quality}

\author{
Carla Franciele Höring ${ }^{1}$; Marlene de Matos Malavasi²; Ubirajara Contro \\ Malavasi $^{2 *}$
}

\begin{abstract}
Resumo
O ensaio objetivou avaliar a influência do armazenamento não controlado na qualidade de sementes de Jatropha curcas L. As sementes utilizadas foram procedentes de um cultivo comercial localizado em Eldorado (MS) submetidas ao beneficiamento manual e amostradas de acordo com o período de armazenamento em um galpão adjacente à sede da propriedade. Os períodos de armazenamento testados equivaleram a 17, 40, 66, 108 e 164 dias. A qualidade das sementes foi determinada pela da quantificação do teor de água, da massa de mil sementes, da germinação, e do vigor por meio do índice de velocidade de germinação (IVG). Os testes de germinação e vigor em laboratório utilizaram as temperaturas constantes de 25 ou $30^{\circ} \mathrm{C}$ e dois substratos de germinação (rolo de papel e entre areia). A porcentagem de germinação e o IVG para sementes com 17 e 40 dias de armazenamento foram de $71,5 \%$ e 29 , enquanto que para as sementes dos demais períodos resultaram em valores de $52 \%, 21 \%$ e $23 \%$ e de 19,21 e 23, respectivamente. Sementes colhidas e armazenadas por até 40 dias em ambiente sombreado não controlado expressaram maior viabilidade e germinaram em menos tempo.

Palavras-chave: Pinhão manso. Germinação. Vigor de sementes. Viabilidade de sementes.
\end{abstract}

\begin{abstract}
This study aimed to evaluate the effect of storage in the quality of Jatropha curcas L. seeds. Seeds were collected from a commercial stand located in Eldorado (MS). Seeds were manually cleaned and stored in an uncontrolled environment facility. Seeds were sampled according to storage period equivalent to 17, 40, 66, 108 and 164 days. Seed quality was determined by determination of seed water content, the seed mass of 1000 seeds, germination and germination velocity index (GVI). Germination and GVI tests used constant temperatures of 25 or $30^{\circ} \mathrm{C}$ and two substrates (sterilized sand and paper rolls). Germination percentage and GVI with seeds stored for 17 and 40 days yielded $71.5 \%$ and 29 while seeds from the other storage periods yielded values of $52 \%, 21 \%$ and $23 \%$, and of 19,21 and 23 , respectively. Recent harvested seeds stored for up to 40 days under uncontrolled environment expressed the highest viability and germinated faster than seeds from the stored from longer periods.

Key words: Physic nut. Germination velocity index. Seed vigour. Seed viability.
\end{abstract}

1 Doutoranda em Agronomia, Universidade Estadual de Londrina, UEL, Londrina, PR, CEP 86051-990. E-mail: carlinhabio@, yahoo.com.br

2 Professor(a) da Universidade Estadual do Oeste do Paraná, UNIOESTE-MCR, PPGA, Marechal Candido Rondon, PR, CEP 85960-000. E-mail: malavasi@unioeste.br; umala@unioeste.br

* Autor para correspondência

Recebido para publicação 29/1 1/2009 Aprovado em 07/04/201 1 


\section{Introdução}

O pinhão manso (Jatropha curcas L.) é uma das opções viáveis ao produtor agrícola para a extração de óleo (MACÊDO et al., 2004), podendo alcançar idade produtiva entre 3 ou 4 anos, e estender a frutificação por até 40 anos (ARRUDA et al., 2004). $\mathrm{O}$ uso de sementes com qualidade torna-se requisito principal para que a espécie possa ser utilizada com sucesso no estabelecimento da cultura (MARCOS FILHO, 2005).

Devido à emissão seqüencial de inflorescências (ALBUQUERQUE et al., 2008) a formação dos frutos em $J$. curcas não ocorre ao mesmo tempo, ou seja, uma mesma planta apresenta frutos com diferentes idades e em diferentes estádios de maturação. Consequentemente, a desuniformidade no processo de formação e maturação dos frutos do pinhão manso força o produtor a fazer a colheita de forma escalonada, o que requer tempo e mão-de-obra, tornando o processo de colheita de sementes uma das fases mais críticas do sistema de produção. Adicionalmente, as sementes colhidas são armazenadas próximas ao local de produção em condições não controladas.

Sementes armazenadas possuem dois tipos principais de água na sua composição: a água livre facilmente removida pelo calor e a água de constituição que está fortemente fixada às células (CARVALHO; NAKAGAWA, 2000). As sementes tendem a absorver ou perder umidade para o ambiente, até atingirem o equilíbrio, quando a umidade relativa do ar do ambiente de armazenamento é modificada (BRAGANTINI, 2005).

A conservação das sementes possui grande importância para a propagação das espécies vegetais, e o armazenamento das sementes, uma vez aplicado de modo adequado, diminui a velocidade de deterioração que se caracteriza por ser um processo irreversível (DELOUCHE; BASKIN, 1973; MELO et al., 1998, apud CABRAL; BARBOSA; SIMABUKURO, 2003).
O presente trabalho objetivou avaliar a influência do período de armazenamento em condições não controladas no local de produção na qualidade de sementes de Jatropha curcas L.

\section{Material e Métodos}

O trabalho foi conduzido na Universidade Estadual do Oeste do Paraná com sementes de Jatropha curcas L. colhidas no município de Eldorado (MS), localizado a $24^{\circ} 42^{\prime}$ latitude sul e $54^{\circ} 14^{\prime}$ ' longitude oeste, a uma altitude média de 342 metros. As sementes originaram-se de um povoamento formado a mais de quatro anos com material procedente de Pedro Juan Caballero, Paraguai. O clima do local da colheita é classificado como subtropical úmido com precipitação média anual de $1.229 \mathrm{~mm}$ distribuídos durante os meses de outubro e março, e temperatura média anual de $24{ }^{\circ} \mathrm{C}$, enquanto o solo apresenta-se arenoso de média fertilidade.

As sementes utilizadas foram colhidas quando os frutos apresentavam a coloração marrom escura, beneficiadas manualmente, e estavam armazenadas em sacos de papel multifoliado empilhados sobre estrados de madeira em um galpão sombreado sem controle de temperatura ou umidade relativa. Devida à desuniformidade da maturação dos frutos, as colheitas foram realizadas pelo produtor nas datas de 17/01, 13/03, 21/04, 25/04 e 13/06 de 2007. De cada uma das datas de colheita retirou-se aleatoriamente uma amostra dois quilogramas de sementes de diversos sacos. Após o transporte ao laboratório, as análises foram iniciadas em 01/07 do mesmo ano representando assim, períodos de armazenamento nas condições acima mencionadas de 164, 108, 66, 40, e 17 dias, respectivamente.

A caracterização física dos propágulos originados de cada período de armazenamento constou da quantificação da massa de mil sementes, utilizando quatro repetições de 25 sementes cada, do teor de água em quatro repetições de 50 sementes (BRASIL, 2009), e da avaliação da qualidade pelos testes de germinação e vigor. 
A avaliação da germinação, realizada em quatro repetições de 25 sementes, retiradas dos tratamentos, correspondentes aos períodos de armazenamento foram semeadas entre areia (autoclavada a $120{ }^{\circ} \mathrm{C}$ durante 20 minutos) em bandejas plásticas de $40 \mathrm{x}$ 30 x $5 \mathrm{~cm}$, e em rolos de papel toalha (umedecidos na proporção de 2,5 vezes o seu peso de água destilada), e em seguida transferidas para câmaras de germinação (BOD) sem luz e a temperaturas constantes de $25 \pm 2$ ${ }^{\circ} \mathrm{C}$, e de $30 \pm 2{ }^{\circ} \mathrm{C}$.

Durante o teste de germinação os substratos foram umedecidos com $250 \mathrm{~mL}$ (substrato entre areia), ou $50 \mathrm{~mL}$ (substrato rolo de papel) de água destilada sempre que necessário para não ressecar o substrato e prejudicar a germinação. As contagens do número de plântulas germinadas foram realizadas diariamente durante 30 dias. Considerou-se semente germinada a protrusão da radícula e a emissão dos cotilédones no substrato rolo de papel, e a presença dos cotilédones acima da superfície do substrato entre areia.

Calcularam-se a percentagem de germinação, o número de dias para inicio e térmico da germinação, e o número de dias necessários para germinação de $50 \%$ de sementes viáveis (T50) de acordo com Orchard (1977). O teste de vigor foi representado pelo índice de velocidade de germinação (IVG) conforme Maguire (1962).

$\mathrm{O}$ estudo foi conduzido em um delineamento inteiramente casualizado em esquema fatorial $2 \times 2 \times 5$ formado por dois substratos (entre areia e rolo de papel), duas temperaturas constantes $\left(25\right.$ ou $\left.30^{\circ} \mathrm{C}\right)$, e cinco períodos de armazenagem com 4 repetições.

Para as análises utilizou-se o programa Sisvar (FERREIRA, 2003). Quando houve diferença estatística as médias foram comparadas com o teste de Tukey a 5\% de probabilidade.

\section{Resultados e Discussão}

Os valores da massa de mil sementes e do teor de água das sementes apresentaram diferença em função dos períodos de armazenamento (Tabela 1). Os teores médios de água das sementes armazenadas por 66 dias e 164 dias foram maiores quando comparados aos das sementes dos demais períodos de armazenagem.

Tabela 1. Teor de água e massa de mil sementes de Jatropha curcas L. em função do período de armazenagem em condições não controladas.

\begin{tabular}{lllllc}
\hline & 17 Dias & 40 Dias & 66 Dias & 108 Dias & 164 Dias \\
\hline Teor de água (\%) & $8,0 \mathrm{~b}$ & $8,0 \mathrm{~b}$ & $8,5 \mathrm{a}$ & $8,1 \mathrm{~b}$ & $8,5 \mathrm{a}$ \\
Massa de mil sementes $(\mathrm{g})$ & $660 \mathrm{a}$ & $680 \mathrm{a}$ & $590 \mathrm{~b}$ & $570 \mathrm{~b}$ & $590 \mathrm{~b}$ \\
\hline
\end{tabular}

Médias seguidas da mesma letra na linha não diferem estatisticamente pelo teste de Tukey a 5\% de probabilidade.

Os resultados da massa de mil sementes indicaram que os períodos de armazenamento de 17 e 40 dias apresentaram valores iguais e maiores do que os quantificados para sementes armazenadas por 66, 108 e 164 dias. Tanto o valor do teor de água como a massa de mil sementes deste ensaio assemelham-se àqueles reportados por Fogaça et al. (2007) com sementes procedentes de Janaúba (MG) colhidas também em 2007 com valores de 7,6\% e $657 \mathrm{~g}$, respectivamente.
O processo de germinação desenvolveu-se de forma rápida e uniforme, iniciando com a protrusão da radícula no quarto dia após a semeadura no substrato rolo de papel nas duas temperaturas testadas. Na germinação em substrato entre areia, as plântulas emergiram entre o quarto e o quinto dia.

As plântulas normais de $J$. curcas originadas dos testes de germinação apresentaram cotilédones, hipocótilo e raiz primária com raízes secundárias bem desenvolvidas e sadias. Conforme enfatizado nas 
Regras para Análise de Sementes (BRASIL, 2009) plântulas normais demonstram ser aptas à produção de plantas normais sob condições favoráveis de campo. As anormalidades manifestadas nas sementes e plântulas no decorrer dos testes foram decorrentes de sementes deterioradas e infestadas por fungos, e de plântulas com deterioração radicular e do hipocótilo no teste de germinação em rolo de papel. Na germinação entre areia observouse a deterioração do hipocótilo.

A análise dos resultados de germinação (Tabela 2) indicou a inexistência de interações entre as fontes de variação substrato, temperatura e períodos de armazenamento das sementes, diferentemente do reportado por Pereira, Santos e Dias (2007) que obtiveram maiores porcentagens de germinação com temperaturas constantes de 30 ou $35{ }^{\circ} \mathrm{C}$, ou ainda alteradas $20-30{ }^{\circ} \mathrm{C}$ com os mesmos substratos utilizados no presente estudo, porém, com sementes procedentes de Janaúna, MG. Fogaça et al. (2007) também obtiveram maiores valores da germinação com sementes procedentes de Janaúna utilizando temperatura constante de $30{ }^{\circ} \mathrm{C}$, ou alterada $20-30$ ${ }^{\circ} \mathrm{C}$ e luz constante, assim como Martins, Machado e Cavasini (2008) com temperatura alternada de 20$30{ }^{\circ} \mathrm{C}$ em substrato areia ou papel e com contagem final aos 10 dias da semeadura.

Tabela 2. Análise de variância dos resultados da germinação de sementes de Jatropha curcas L. em função do substrato, da temperatura, e do período de armazenagem em condições não controladas.

\begin{tabular}{llll}
\hline FONTE DE VARIAÇÃO & GL & F & p-valor \\
\hline Substrato (S) & 1 & 0,345 & 0,5595 \\
Temperatura (T) & 1 & 3,455 & 0,0682 \\
Período de armazenamento(P) & 4 & 24,073 & 0,0000 \\
(S) X (T) & 1 & 0,038 & 0,8456 \\
(S) $x(P)$ & 4 & 0,153 & 0,9608 \\
(T) $x(P)$ & 4 & 1,948 & 0,1149 \\
(S) $x(T) \times(P)$ & 4 & 0,086 & 0,9864 \\
ERRO & 57 & & \\
CV $=15,36$ & & & \\
\hline
\end{tabular}

As porcentagens de germinação (Tabela 3) foram estatisticamente maiores com sementes armazenadas por 17 e 40 dias (média de 71\%) comparadas com aquelas armazenadas por 66, 108 e 164 dias (média de $52 \%$ ). Os maiores valores de germinação do presente trabalho são menores dos que os obtidos com sementes da safra 2007 procedentes do norte de Minas Gerais por Pereira, Santos e Dias (2007) que atingiram valores de 95 a $98 \%$. 
Tabela 3. Porcentagem e dias de germinação de sementes de Jatropha curcas L. em função do período de armazenamento em condições não controladas.

\begin{tabular}{cllll}
\hline \multirow{2}{*}{ DIAS } & \multicolumn{4}{c}{ GERMINAÇÃO } \\
\cline { 2 - 5 } & Total(\%) & Início(dias) & Final(dias) & T50(dias) \\
\hline 17 & $72 \mathrm{a}$ & $4,25 \mathrm{a}$ & $17,06 \mathrm{a}$ & $7,50 \mathrm{c}$ \\
40 & $71 \mathrm{a}$ & $4,00 \mathrm{a}$ & $13,75 \mathrm{~b}$ & $7,25 \mathrm{c}$ \\
66 & $48 \mathrm{~b}$ & $4,25 \mathrm{a}$ & $11,00 \mathrm{c}$ & $10,75 \mathrm{a}$ \\
108 & $52 \mathrm{~b}$ & $4,25 \mathrm{a}$ & $10,87 \mathrm{c}$ & $10,25 \mathrm{a}$ \\
164 & $55 \mathrm{~b}$ & $4,25 \mathrm{a}$ & $10,87 \mathrm{c}$ & $9,00 \mathrm{~b}$ \\
\hline
\end{tabular}

Médias seguidas da mesma letra na coluna não diferem estatisticamente pelo teste de Tukey a $5 \%$ de probabilidade.

Uma alternativa de metodologia à condução do teste de germinação das sementes de pinhão manso considera a avaliação final aos 10 dias de acordo com Pereira, Santos e Dias (2007) e resultados externados por Martins, Machado e Cavasini (2008). Neste ensaio, após 7 dias do início da germinação, sementes armazenadas por 17 e 40 dias apresentaram 50\% de sementes germinadas das quais $71 \%$ foram classificadas como plântulas normais. Sementes com maior vigor apresentaram as maiores porcentagens de plântulas normais assemelhando-se aos resultados de Grisi et al. (2007) que obtiveram maior porcentagem de plântulas normais com sementes de Helianthus annus de maior vigor.
A porcentagem de germinação com sementes de pinhão manso armazenadas por 17 dias assemelha-se à citada por Lima et al. (2007) com Ricinus communis L. Para a germinação de sementes de cerejeira, Albrecht, Albuquerque e Silva (1986) verificaram que a temperatura de $30^{\circ} \mathrm{C}$ foi considerada a ideal, pois resultou na maior porcentagem de germinação em um intervalo relativamente curto, e para o substrato a melhor germinação foi obtida com rolo de papel, embora não tenha apresentado o maior índice de velocidade de germinação (IVG).

A análise dos resultados do IVG mostrou diferença significativa $(\mathrm{P}<0,05)$ apenas em função do período de armazenamento das sementes. O maior IVG foi calculado com sementes armazenadas

Tabela 4. Índice de velocidade de germinação (IVG) das sementes de Jatropha curcas L. em função do período de armazenamento em condições não controladas.

\begin{tabular}{ll}
\hline DIAS & MÉDIA \\
\hline 17 & $29 \mathrm{a}$ \\
40 & $29 \mathrm{a}$ \\
66 & $19 \mathrm{~b}$ \\
108 & $21 \mathrm{~b}$ \\
164 & $23 \mathrm{~b}$ \\
\hline
\end{tabular}

Médias seguidas da mesma letra na coluna não diferem estatisticamente pelo teste de Tukey a $5 \%$ de probabilidade. 
Os valores calculados do IVG neste trabalho são comparáveis aos calculados por Pereira, Santos e Dias (2007) os quais variaram de 15 a 29 com o substrato rolo de papel, e de 24 a 28 com o substrato entre areia nas temperaturas de 25 e $30^{\circ} \mathrm{C}$, respectivamente.

\section{Conclusões}

Para sementes de Jatropha curcas L. armazenadas em condições de sombra não controladas, quanto maior o tempo de armazenamento maior a perda de massa das sementes. Sementes colhidas e armazenadas por até 40 dias em condições de sombra não controladas expressam maior viabilidade e germinaram em menos tempo.

\section{Referências}

ALBRECHT, J. M. F.; ALBUQUERQUE, M. C. L. F.; SILVA, V. S. M. Influência da temperatura e do tipo de substrato na germinação de sementes de cerejeira. Revista Brasileira de Sementes, Brasília, v. 8, n. 1, p. 4955, 1986.

ALBUQUERQUE, F. A.; OLIVEIRA, M. I. P.; LUCENA, A. M. A.; BARTOLOMEU, C. R. C.; BELTRÃO, N. E. M. Crescimento e desenvolvimento do pinhão manso: $1^{\circ}$ ano agrícola. Campina Grande: Embrapa Algodão, 2008. $21 \mathrm{p}$.

ARRUDA, F. P.; BELTRÃO, N. E. M.; ANDRADE, A. P.; PEREIRA, W. E.; SEVERINO, L. S. Cultivo de pinhão- manso (Jatropha curca L.) como alternativa para o semi-árido nordestino. Revista Brasileira de Oleaginosas e Fibrosas, Campina Grande, v. 8, n. 1, p. 789-799, 2004.

BRAGANTINI, C. Alguns aspectos do armazenamento de sementes e grãos de feijão. Santo Antônio de Goiás: Embrapa Arroz e Feijão, 2005. 28 p.

BRASIL. Ministério da Agricultura, Pecuária e Abastecimento. Regras para análise de sementes. Brasília: MAPA/ACS, 2009. 399 p.

CABRAL, E. L.; BARBOSA, D.C. A.; SIMABUKURO, E. A. Armazenamento e germinação de sementes de Tabebuia Aurea (manso) Benth. \& Hook. f. ex. S. Moore. Acta Botanica Brasilica, Feira de Santana, v. 17, n. 4, p. 609-617, 2003.

CARVALHO, N. M.; NAKAGAWA, J. Sementes: ciência, tecnologia e produção. 4. ed. Jaboticabal: FUNEP, 2000. 588 p.

DELOUCHE, J. C.; BASKIN, C. C. Accelerated aging techniques for predicting the relative storability of seed lots. Seed Science and Technology, v. 1, p. 427-52, 1973.

FERREIRA, D. F. Programa de análises estatísticas (Statistical Analysis Software) e planejamento de experimentos. Lavras: UFLA, 2003.

FOGAÇA, C. A.; SILVA, L. L; POLIDORO, J. C.; BREIER, T. B.; LELES, P. S. S. Metodologia para a condução do teste de germinação em sementes de Jatropha curcas L. In: CONGRESSO BRASILEIRO DE PLANTAS OLEAGINOSAS, ÓLEOS, GORDURAS E BIODIESEL, 4., 2007, Varginha. Anais... Varginha: Universidade Federal de Lavras, 2007. p. 1351-1357.

GRISI, P. U.; CAIXETA, F.; SANTOS, M. S.; SOUZA, G.F.M.V.; SÁ JÚNIOR, A.; SANTANA, D. S. Avaliação do vigor em diferentes épocas de armazenamento sobre a qualidade de sementes de girassol. Horizonte Cientifico, Uberlândia, v. 1, n. 7, p. 1-14, 2007.

LIMA, M. G. S.; MENDES, C. R.; MORAES, D. M.; LOPES, N. F.; RODRIGUES, M. A. V. Caracterização da qualidade fisiológica de sementes de mamona cultivar guarani. Revista Brasileira de Biociências, Porto Alegre, v. 5, p. 675-677, 2007. Suplemento 2.

MACÊDO, N. E.; BELTRÃO, A. P. A.; PEREIRA, W. E.; SEVERINO, L. S. Cultivo de pinhão manso (Jatropha curcas L.) como alternativa para o semi-árido nordestino. Revista Brasileira de Oleaginosas e Fibrosas, Capina Grande, v. 8, n. 1, p. 789-799, 2004.

MAGUIRE, J. D. Speed of germination-aid selection emergence and vigor. Crop Science, Madison, v. 2, n. 1, p. 176-7, 1962.

MARCOS FILHO, J. Fisiologia de plantas cultivadas. Piracicaba: FEALQ, 2005. 495 p.

MARTINS, C. C.; MACHADO, C. G.; CAVASINI, R. Temperatura e substrato para o teste de germinação de sementes de pinhão-manso. Ciência Agrotecnica, Lavras, v. 32, n. 3, p. $863-868,2008$.

ORCHARD, T. J. Estimating the parameters of plant seedling emergence. Seed Science and Technology, Bassersdorf, v. 5, n. 5, p. 61-69, 1977.

PEREIRA, M. D.; SANTOS, D. C. F.; DIAS, L. A. S. Germinação de sementes de pinhão manso (Jatropha curcas L.) em diferentes temperaturas e substratos. 2007. Disponível em <http://www.biodiesel.gov.br/docs/ congresso2007/agricultura/47.pdf $>$. Acesso em: 03 out. 2008. 